Gina Lafreniere MSc, $\dagger$

Brian Milne MD FRCPC, ${ }^{*} \dagger$

Donald G. Brunet MD FRCPC, $\ddagger$

Michael A. Adams PhD, $\dagger$

Joel L. Parlow MD FRCPC ${ }^{\star} \dagger$

\title{
Autonomic circulatory and cerebrocortical responses during increas- ing depth of propofol sedation/hypnosis in humans
}

Purpose: To describe the relative effects of graded central nervous system (CNS) depression, using increasing propofol infusion rates, on neurovegetative brainstem-mediated circulatory control mechanisms and higher cortical activity in healthy humans.

Methods: Propofol was administered using an infusion scheme designed to achieve three target blood concentrations in ten healthy volunteers. Blood propofol concentrations and sedation scores were determined at baseline, during the three propofol infusion levels, and 30 min into the recovery period. Electroencephalographic (EEG) power was measured in three frequency bands to quantify cortical activity, and autonomic heart rate control was quantified using spontaneous baroreflex assessment and power spectral analysis of pulse interval.

Results: Sedation scores closely paralleled propofol blood concentrations $(0,0.53 \pm 0.34,1.24 \pm 0.21,3.11 \pm$ 0.80 , and $0.96 \pm 0.42 \mu \mathrm{g} \cdot \mathrm{mL}^{-1}$ at baseline, three infusion levels and recovery respectively), and all subjects were unconscious at the deepest level. Indices of autonomic heart rate control were decreased only at the deepest levels of CNS depression, while EEG effects were apparent at all propofol infusion rates. These EEG effects were frequency specific, with power in the beta band being affected at light levels of sedation, and alpha and delta power altered at deeper levels.

Conclusions: The results of this study support a relative preservation of neurovegetative circulatory control mechanisms during the early stages of CNS depression using gradually increasing rates of infusion of propofol. Indices of circulatory control did not reliably reflect depth of sedation.

Objectif: Décrire les effets relatifs d'une dépression graduée du système nerveux central (SNC) sur les mécanismes d'origine centrale du contrôle neurovégétatif de la circulation, et l'activité corticale supérieure chez des humains sains, en utilisant des perfusions de propofol à vitesses croissantes.

Méthode : Le propofol a été administré, chez dix volontaires en santé, selon un schéma de perfusion conçu pour atteindre trois concentrations sanguines cibles. Les concentrations sanguines de propofol et les scores de sédation ont été déterminés au départ, pendant les trois régimes de perfusion de propofol et à 30 min pendant la récupération. La puissance électroencéphalographique (EEG) a été mesurée selon trois bandes fréquentielles pour quantifier l'activité corticale, et le contrôle autonome de la fréquence cardiaque a été mesuré à l'aide d'une évaluation baroréflexe spontanée et de l'analyse spectrale de la puissance de l'intervalle pulsé.

Résultats : Les scores de sédation ont présenté un étroit parallélisme avec les concentrations sanguines de propofol $\left(0 ; 0,53 \pm 0,34, I, 24 \pm 0,21 ; 3,11 \pm 0,80\right.$, et $0,96 \pm 0,42 \mu \mathrm{g} \cdot \mathrm{mL}^{-1}$ au début, pendant les trois perfusions et la récupération, respectivement), et tous les sujets ont connu un profond sommeil. Les indices de contrôle autonome de la fréquence cardiaque ont diminué seulement au moment de la plus profonde dépression du SNC, tandis que les effets EEG ont été apparents pour toutes les vitesses de perfusion du propofol. Ces effets EEG différaient selon les fréquences, la puissance de la bande bêta étant affectée à de bas niveaux de sédation et les bandes alpha et delta étant modifiées à des niveaux plus profonds.

Conclusion : Les résultats de l'étude entretiennent une relative préservation des mécanismes de contrôle neurovégétatif de la circulation pendant les premiers stades de la dépression du SNC quand on utilise des vitesses de perfusion de propofol qui augmentent graduellement. Les indices de contrôle circulatoire ne reflètent pas fidèlement la profondeur de la sédation.

From the Departments of Anesthesiology, ${ }^{*}$ Pharmacology, $\dagger$ and Medicine, $\ddagger$ Queen’s University, Kingston, Ontario.

Address correspondence to: Dr. Joel L. Parlow, Department of Anesthesiology, Kingston General Hospital, 76 Stuart Street, Kingston, Ontario, K7L 2V7 Canada. Phone: 613-548-7827; Fax: 613-548-1375; E-mail: parlowj@post.queensu.ca

Financial support: Propofol blood concentrations funded by Zeneca Pharma Ltd.

Presentations: Interim data from this study were presented in poster form at the Canadian Anaesthetists' Society annual meeting, June 17, 1996.

Accepted for publication February 6, 2000.

CAN J ANESTH $2000 / 47: 5 /$ pp 441-448 
$\mathrm{D}$ RUGS which depress the central nervous system (CNS) such as sedatives and general anesthetics act through a variety of mechanisms, including nonspecific ion channel effects and specific receptor-mediated systems. ${ }^{1}$ Although higher (cortical) brain activity is generally affected before the more primitive life-sustaining brainstem functions, the relative degree of depression of different regions of the CNS depends on the specific agent as well as its tissue concentration. ${ }^{1}$ The intravenous general anesthetic propofol is commonly administered by continuous infusion, the rate of which can be titrated to produce a spectrum of effects ranging from conscious sedation to surgical anesthesia. Propofol has welldescribed effects on the electroencephalogram (EEG), which has been studied as a means of assessing depth of sedation. ${ }^{2,3}$ Propofol also depresses autonomic circulatory control, as evidenced by decreased arterial baroreflex sensitivity and heart rate variability. ${ }^{4-7}$ The hypotensive action of propofol seen at higher infusion rates likely occurs at the level of both the cardiovascular centres of the brainstem and peripheral sites. ${ }^{8,9}$

The effects of propofol on brainstem-mediated circulatory control at subanesthetic concentrations has not been studied previously. The objective of the present study was to document the relative effects of graded increases in depth of CNS depression using propofol on autonomic circulatory control in healthy humans, with respect to cerebral cortical activity. Secondarily, we wished to explore whether indices of autonomic control could play a potential role as a continuous estimate of depth of sedation. Graded increases in rates of propofol infusion were used at doses calculated to target clinical states of light sedation, deep sedation and unconsciousness.

Materials and methods Experimental protocol

After approval by the Queen's University Research Ethics Board, ten healthy human volunteers (aged $27 \pm$ 3 yr) gave written informed consent to participate in this trial. All subjects were American Society of Anesthesiologists class I, and were nonsmokers and not receiving medications acting on the CNS or cardiovascular system. Prior to the study session, subjects took nothing by mouth for eight hours, used no caffeine or alcohol for $12 \mathrm{hr}$ and avoided strenuous exercise for 24 hr. The studies were carried out in a quiet operating suite, and subjects were familiarized with the study environment before proceeding. Under local anesthesia, a large bore intravenous catheter was inserted into each antecubital fossa. Lactated Ringer's solution was infused at maintenance rates through one catheter and blood samples were withdrawn from the second catheter. Lead II of the electrocardiogram (Tektronix, Beaverton, OR) and oxygen saturation (Satlite, Datex, Helsinki, Finland) were monitored continuously. Blood pressure was measured non-invasively using the technique of finger plethysmography (Finapres 2300, Ohmeda, Madison, WI). The Finapres has been shown to track reliably beat-by-beat changes in blood pressure, compared with intra-arterial measurements, during a variety of methods of autonomic testing. ${ }^{10,11}$ Subjects breathed spontaneously with no artificial airway, and oxygen was administered by nasal prongs if necessary to maintain oxygen saturation of at least $96 \%$. Tidal volume and respiratory rate were monitored using the Respitrace ${ }^{\circledR}$ (Nims Inc., Miami Beach, FL), with chest and abdominal bands used and calibration performed in supine and standing positions prior to each study session. Propofol (Diprivan, Zeneca Pharma, Mississauga, ON, Canada) was administered using a programmable electronic syringe pump (Model AS40A, Baxter, Deerfield, IL) to sequentially achieve three target plasma propofol concentrations (Table I). These concentrations have previously been shown to result in increasingly sedative effects (P1 and P2), and full general anesthesia (P3). ${ }^{12-14}$ Venous blood samples were drawn five and 25 min after commencing each infusion level and were stored in EDTA-added tubes. The tubes were centrifuged for five minutes, separated, and the serum stored at $-80^{\circ} \mathrm{C}$. Serum propofol concentrations were measured using high performance liquid chromatography, ${ }^{15}$ with limits of quantitation between 0.0625 and $4.0 \mu \mathrm{g} \cdot \mathrm{mL}^{-1}$, variability of $6.4-7.7 \%$ (Dr. France Varin, Université de Montréal).

Concurrent with the blood sampling times, a modified Observer's Assessment of Alertness/Sedation Scale ${ }^{16}$ was administered: $1=$ wide awake, $2=$ slightly drowsy, $3=$ drowsy, $4=$ very drowsy but responding to verbal commands, $5=$ rousable to mild physical stimulation, $6=$ not rousable. For reproducibility, one observer performed all of the sedation scores.

\section{Cardiovascular data collection and analysis}

Fifteen minute recordings of electrocardiogram and blood pressure signals were carried out beginning 10 min after the onset of each infusion level. After appropriate calibration, these signals were digitized by a 12 bit analog digital converter at a sampling frequency of $1000 \mathrm{~Hz}$ (metrabyte DAS-16, Taunton, MA), all intervals between successive $R$ waves ( $R R$ intervals) on the electrocardiogram were measured and paired with the corresponding systolic and diastolic blood pressures for each beat. These values were stored on computer in numeric form. 
TABLE I Propofol infusion scheme

\begin{tabular}{llllll}
\hline Study level & $\begin{array}{l}\text { Target propofol } \\
\text { concentration } \\
\mu g \cdot m L^{-1}\end{array}$ & $\begin{array}{l}\text { Propofol concentration } \\
\text { achieved (mean } \pm S D) \\
\mu g \cdot m L^{-1}\end{array}$ & $\begin{array}{l}\text { Loading dose } \\
\text { over 20 sec } \\
\mu g \cdot \mathrm{Kg}^{-1}\end{array}$ & $\begin{array}{l}\text { Infusion rate } \\
\text { for } 10 \mathrm{~min} \\
\mu \mathrm{g} \cdot \mathrm{Kg}^{-1} \cdot \mathrm{min}^{-1}\end{array}$ & $\begin{array}{l}\text { Infusion rate for } \\
\text { next } 15 \mathrm{~min} \\
\mu \mathrm{m} \cdot \mathrm{Kg}^{-1} \cdot \mathrm{min}^{-1}\end{array}$ \\
\hline $\mathrm{B}$ & 0 & 0 & 0 & 0 & 0 \\
$\mathrm{P1}$ & 0.8 & $0.53 \pm 0.34$ & 267 & 45 & 33 \\
P2 & 1.6 & $1.24 \pm 0.21$ & 270 & 80 & 58 \\
P3 & 3.2 & $3.11 \pm 0.80$ & 530 & 160 & 116 \\
\hline
\end{tabular}

Study levels correspond to baseline (B), and three propofol infusion rates targeted to achieve light sedation (P1), heavy sedation (P2), and unconsciousnes (P3).

Propofol concentrations achieved reported as mean \pm SD of two samples drawn at the beginning and end of recordings made at each study level.

TABLE II Respiratory and hemodynamic data

\begin{tabular}{llllll}
\hline & $B$ & $P 1$ & $P 2$ & $P 3$ & $R$ \\
\hline Systolic blood pressure $(\mathrm{mmHg})$ & $128 \pm 10$ & $124 \pm 9$ & $105 \pm 10^{*}$ & $94 \pm 11^{*}$ & $127 \pm 13$ \\
R-R interval $(\mathrm{msec})$ & $1080 \pm 138$ & $1061 \pm 84$ & $1014 \pm 91$ & $940 \pm 94^{*}$ & $1051 \pm 94$ \\
Respiratory rate $\left(\right.$ breaths $\left.\cdot \mathrm{min}^{-1}\right)$ & $15 \pm 2$ & $16 \pm 2$ & $17 \pm 2$ & $18 \pm 3^{*}$ & $14 \pm 3$ \\
Tidal volume $(\mathrm{mL})$ & $389 \pm 103$ & $350 \pm 120$ & $328 \pm 94$ & $304 \pm 89^{*}$ & $451 \pm 204$ \\
Minute ventilation $\left(\mathrm{mL} \cdot \mathrm{min}^{-1}\right)$ & $5740 \pm 1550$ & $5521 \pm 1717$ & $5685 \pm 1862$ & $5533 \pm 2201$ & $5900 \pm 1487$ \\
\hline
\end{tabular}

Values are mean \pm SD. Time periods correspond to baseline $(\mathrm{B})$, three propofol infusion rates targeted to achieve light sedation $(\mathrm{Pl})$, heavy sedation (P2), and unconsciousness (P3), and during recovery one half hour after discontinuation of propofol (R).

${ }^{*} P<0.05$ vs respective baseline values.

The technique of spontaneous baroreflex analysis was used to calculate sensitivity of the cardiac baroreflex. ${ }^{17,18}$ The computer software examined each 15 min data recording to select all sequences of three or more successive heart beats in which there were concordant increases or decreases in systolic blood pressure (SBP) and RR intervals. A linear regression was applied to each of the sequences and an average regression slope was calculated for the sequences detected during each recording period. The slope of this regression represents the mean cardiac baroreflex sensitivity for that time period, and has been shown to reflect values obtained at the level of the resting blood pressure using the vasoactive drug method. ${ }^{19}$

Frequency analysis of $\mathrm{R}-\mathrm{R}$ interval variability was performed using coarse-graining spectral analysis. The details of this technique have been described previously. ${ }^{20}$ From each study period an artifact-free stationary time series of 560 consecutive R-R intervals (representing approximately 8-10 min) was selected. A fast Fourier transformation was applied to the time series to generate a power spectral curve. This power spectrum describes $\mathrm{R}-\mathrm{R}$ interval power (units of $\left.\mathrm{ms}^{2} \cdot \mathrm{Hz}^{-1}\right)$ as a function of frequency $(\mathrm{Hz})$. The R-R interval power is calculated as the integration of the area under the curve over any given frequency range. Spectral power was calculated over the total frequency range ( 0 to $0.50 \mathrm{~Hz}$ ), as well as the low ( 0 to 0.15 $\mathrm{Hz})$ and high $(0.15$ to $0.50 \mathrm{~Hz})$ frequency ranges.

\section{Electroencephalographic data collection and analysis}

Continuous EEG monitoring was used throughout the study session. Specific time sequences were selected for analysis to correspond with the time periods used for the cardiovascular data analysis (above). Four-channel EEG recordings were made continuously during the experiment (Model 12 Neurodata Acquisition system, Grass Instrument Division, Astromed Inc., W. Warwick, RI). Calibration was performed with an $11 \mathrm{~Hz} 100 \mu \mathrm{V}$ peak to peak sine wave signal applied to the inputs of each differential amplifier. The recording montage was International 10-20 system electrodes $\mathrm{O} 1, \mathrm{C} 4, \mathrm{C} 3, \mathrm{O} 2$ referenced to linked earlobes. Data from C3 to linked earlobes was used in the subsequent analysis. Filter settings ( $1 / 2$ amplitude) of $0.3 \mathrm{HZ}$ (high pass) and $100 \mathrm{Rz}$ (low pass) were used during acquisition. Each channel was digitized at $125 \mathrm{~Hz}$ using a microcomputer with Codas ${ }^{\circledR}$ hardware and software (Dataq Instruments Inc, Akron, $\mathrm{OH}$ ). Using custom software each four second epoch of EEG was displayed on a computer terminal and artefacts identified. Any artifact in a foursecond epoch resulted in exclusion of that segment from further analysis. Only small numbers of epochs 


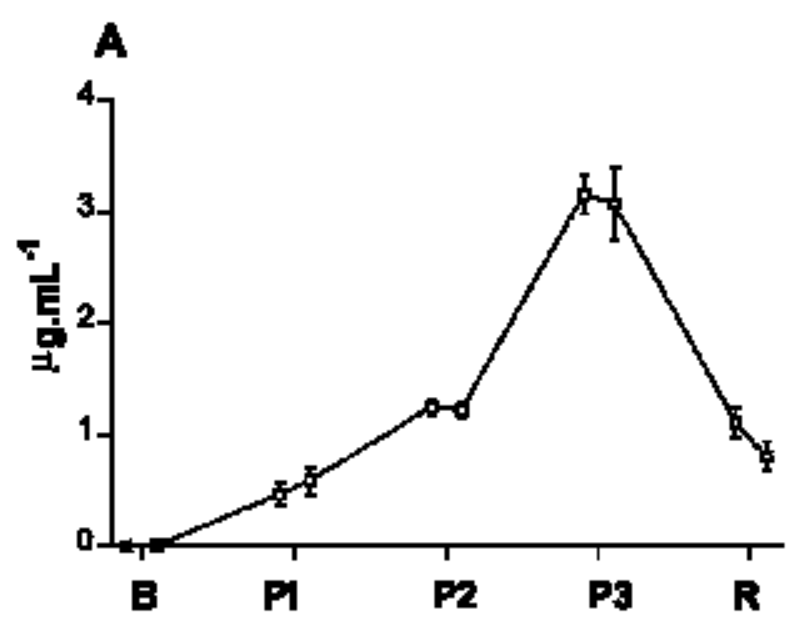

B

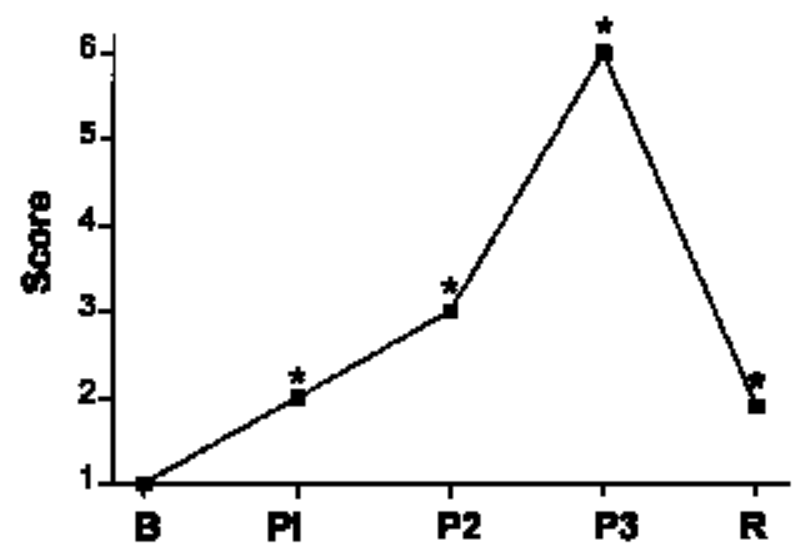

FIGURE I $A$. Propofol blood concentrations (mean \pm SEM) at baseline (B), three propofol infusion rates targeted to achieve light sedation (P1), heavy sedation (P2), and unconsciousnes (P3), and during recovery one half hour after discontinuation of propofol (R). The two symbols for each infusion rate represent the concentration determined at the beginning and end of the respective data collection periods. $B$. Sedation scores (median, 95\% confidence interval) at the same time periods as in $A$, ranging from wide awake (1) to unrousable to physical stimulation $(6) .{ }^{*} P<0.05$ from baseline $(\mathrm{B})$.
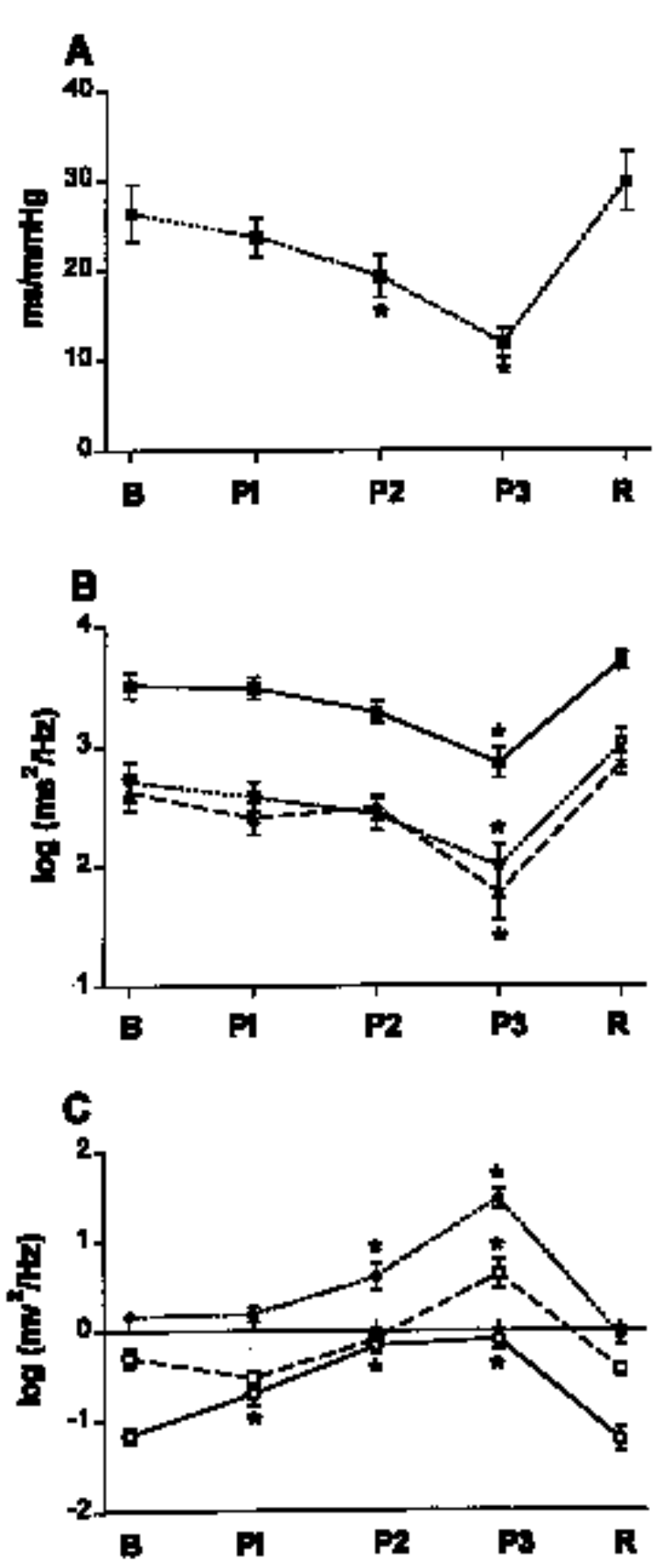

FIGURE 2 Indices of autonomic heart rate control and cortical activity at each of the study periods. A: Spontaneous baroreflex (SBR) slope. $B$ : RR interval power by frequency ranges (total power, 0-0.5 Hz, closed squares; low frequency, 0-0.15 Hz, open triangles; high frequency, $0.15-0.5 \mathrm{~Hz}$, closed triangles). $C$ : Electroencephalographic (EEG) power in the delta band (0.25$3.75 \mathrm{~Hz}$, closed diamonds), alpha band (8.0-11.75 Hz, open squares), and beta band $(12.0-20.0 \mathrm{~Hz}$, open circles $)$. All data reported as mean $\pm \mathrm{SEM},{ }^{*} P<0.05$ from baseline $(\mathrm{B})$. 
(12.0 - $20.0 \mathrm{~Hz}$ bins) bands, along with total power from 0.25 to $20.0 \mathrm{~Hz}$ were calculated for each study condition, standardized by the number of artifact free epochs available for analysis.

\section{Statistical analysis}

Parametric data were analyzed using one-way repeated measures analysis of variance (ANOVA). Where significant $(P<0.05)$ Tukey's test was performed post hoc. Log transformation was applied to non-normally distributed data (spectral power). Categorical data (sedation scores) were compared using Friedman repeated measures ANOVA on ranks.

Results

The propofol infusion scheme used resulted in propofol blood concentrations which were constant from the beginning to the end of each recording period at each infusion level (Figure 1A, Table I). Sedation scores closely paralleled the propofol blood concentrations (Figure 1B), and all subjects were unconscious and unresponsive at level P3.

Mean R-R interval and SBP decreased with increasing infusion level, with significant changes occurring for SBP at the two deepest levels and for RR interval at the P3 level (Table II). Respiratory rate increased and tidal volume decreased gradually with increasing propofol (Table II), with significant changes occurring at $\mathrm{P} 3(P=0.013$ for respiratory rate and $P=0.021$ for tidal volume). Accordingly, minute ventilation remained constant throughout the experimental period (Table II).

Measures of heart rate control also showed changes at the higher infusion levels (Figure 2), with baroreflex slope decreasing at P2 and P3, and heart rate variability decreasing in all frequency ranges only at P3. All parameters returned to baseline at the recovery period $\mathrm{R}$.

Electroencephalographic changes were noted at lower propofol infusion rates than necessary to affect cardiovascular control variables; the course of EEG changes depended on the specific frequency band (Figure 2C). The earliest increases in power occurred at $\mathrm{Pl}$ in the beta $(12-20 \mathrm{~Hz})$ band, with the delta $(0.25-3.75 \mathrm{~Hz})$ band increases occurring at P2 with a further peak at $\mathrm{P} 3$, and alpha $(8-11.75 \mathrm{~Hz})$ band changes occurring only at the P3 level.

\section{Discussion}

The aim of this study was to document indices of cortical function and autonomic circulatory control concurrently during progressively increasing depth of CNS depression. The main findings are: 1) an early increase in power in the beta band of EEG at light levels of sedation, followed by progressive increases in alpha and delta bands, and 2) relative preservation of heart rate control at lighter levels of sedation with a sharp decrease under full anesthesia. Our findings, using this model of progressive depth of sedation/anesthesia, are novel in confirming the notion that lower "vegetative" function is spared in relation to higher brain activity, and suggest that measures of autonomic circulatory control would not likely be useful as a continuous estimate of depth of sedation.

\section{Methodology}

The general anesthetic propofol was used in this study to provide a model of gradual depression of the CNS. The drug is easily titrated in order to target specific blood concentrations, and therefore can be used to establish graded depths of sedation, unconsciousness and surgical anesthesia. ${ }^{21,22}$ The infusion scheme chosen allowed a constant propofol blood concentration to be maintained at each study period (Figure 1A), thus enabling the calculation of EEG and autonomic parameters at a steady state. Propofol is thought to facilitate the inhibitory effects of gamma aminobutyric acid (GABA) on the CNS by binding to specific GABA receptor sites. This action is similar to that of other CNS depressant agents such as benzodiazepines, barbiturates and volatile anesthetics. ${ }^{1}$ However, it is not known whether the specific relationship between cortical and cardiovascular depression determined in the current study can be generalized to other CNS depressant drugs.

The study population consisted of young healthy subjects in order to minimize the impact of coexisting disease or medications on the EEG and cardiovascular measures. The relative autonomic effects of graded propofol infusions in patients with cardiovascular or neurological disease states may be quite different, and clinical applicability of the results would necessitate further studies in surgical patients. Although the study environment was comfortable and controlled, factors such as stress and anxiety may also influence these measures, presumably through a change in relative sympathovagal balance. Indices of autonomic circulatory control have been shown by our group and numerous other investigators to be quite stable over time and between study days at baseline conditions in a variety of study populations. ${ }^{19,23-25}$ For this reason a time control group was not justified, and the changes in measurements over time can be assumed to be due primarily to drug effects at the different infusion rates. In addition, although the investigators administering the protocol were unblinded and could have been 
biased in the assignment of sedation scores, the drug infusion scheme was designed to target specific plasma concentrations, rather than titrating to sedation score. Finally, the cardiovascular and EEG data were objective, and analysis was carried out off-line by investigators blinded to infusion level.

\section{Autonomic circulatory control}

The techniques of spontaneous baroreflex analysis and power spectral analysis of heart rate variability were employed as tools to investigate the neurovegetative mechanisms modulating fine cardiovascular control. These methods have been validated in previous investigations, and allow the quantification of brainstemmediated sympathovagal influences on the heart under a variety of conditions. ${ }^{19,26-29}$

General anesthetics have been shown to depress both the sympathetic and parasympathetic influence on the heart, with the resulting level of sympathovagal balance dependent on the agent studied. Most previous studies have documented the effects of induction of general anesthesia on cardiovascular control, while few have explored the effects of graded increases in depth of CNS depression with specific agents. Propofol has been shown to depress sympathetic neuronal activity and cardiac baroreflex sensitivity after induction doses. ${ }^{4,7,9,30}$ In addition, a shift to sympathetic predominance has been shown after induction, as evidenced by an increase in low frequency relative to high frequency power. ${ }^{31,32}$ However, during steady state infusions at 54 and 108 $\mu \mathrm{g} \cdot \mathrm{kg} \cdot \mathrm{min}^{-1}$ propofol did not decrease baroreflex sensitivity in humans. ${ }^{5}$ Respiratory sinus arrhythmia, another index of vagal heart rate control, has been purported to provide an index of depth of sedation, although changes in this variable were studied during stimulating procedures at fixed rates of infusion of several anesthetic drugs. ${ }^{3}{ }^{3} \mathrm{~A}$ number of factors have complicated previous analyses of autonomic control in the anesthetic setting, including the stimulatory effects of airway manipulation and surgical stimulation, as well as the variety of coinduction drugs commonly used. These factors render the attribution of autonomic responses to the specific pharmacologic effects of propofol quite difficult, as opposed to the current study design.

Propofol is known to reduce blood pressure by both vasodilatory and myocardial depressive activity, ${ }^{34}$ with a growing body of evidence that depression of central sympathetic influences dominate over peripheral actions in reducing blood pressure. ${ }^{8,9,30}$ Previous investigations have demonstrated that the central action of propofol in depressing sympathetic neuronal firing predominates during infusion at a wide variety of rates, whereas only bolus injections of high doses of propofol, superim- posed on barbiturate anesthesia, elicited evidence of additional direct vascular/cardiac depression. ${ }^{9}$ Similarly, propofol infusion into the brachial artery in conscious humans caused no direct vascular responses compared with sodium nitroprusside infusion but, rather, inhibited the sympathetic neural input to the vasculature. ${ }^{8}$ Finally, Ebert et al. demonstrated, in human volunteers, a reduction in efferent muscle sympathetic nerve activity and reduced baroreflex sensitivity with propofol leading to considerable hypotension. ${ }^{30}$ Thus, it is most likely that the blood pressure effects observed during the current protocol at higher propofol infusion rates resulted primarily from inhibition of central circulatory control mechanisms rather than peripheral depressive actions. ${ }^{8,9,30}$

Respiratory influences such as rate, tidal volume and carbon dioxide tension can also affect indices of autonomic control. ${ }^{35}$ General anesthesia usually involves major changes in respiratory function including a change from spontaneous to controlled ventilation. In the current study all patients maintained spontaneous ventilation with no change in oxygen saturation, and both respiratory rate and tidal volume were monitored. Respiratory rate increased and tidal volume decreased by approximately $20 \%$ at the deepest level (P3); these changes could potentially have had some effect on the autonomic measures. However, minute ventilation (and therefore presumably carbon dioxide tension) remained constant, suggesting that these factors did not likely play a significant role in the major changes seen in indices of autonomic control at P3.

\section{Electroencephalographic effects}

There are numerous signal processing methods that may be used to describe EEG signals and relationships in multi-channels recordings. ${ }^{36}$ Since the objective of our study was to assess concurrent changes in cardiovascular variables and the EEG, we chose the fast Fourier transformation without further processing as a robust way of quantifying EEG for these comparisons. More complex processing of EEG signals such as bispectral analysis have been used in this setting, but lack multiple channel discrimination achieved using raw data. ${ }^{36,37}$ Our EEG results are similar to those reported by others, $2,38,39$ showing increases in beta power with low dose infusions, and extend these observations to higher plasma concentrations of propofol, where marked increases in delta and alpha frequency power occur.

\section{Clinical implications}

This study provides evidence that, with gradually 
increasing depth of CNS depression, the "subcortical" autonomic responses are relatively preserved with respect to higher cortical function. This provides for a protective system that allows the controlled use of sedative/hypnotic drugs, which frequently possess cardiovascular side effects, without impairing the compensatory responses needed to buffer these effects. In addition, these data suggest that the measurement of cardiovascular reflex responses would not yield a reliable continuous index of depth of sedation, while further refinement of EEG signal processing may be more promising. ${ }^{2,39,40}$

In conclusion, indices of cortical function and cardiovascular control were studied in healthy volunteers during increasing depth of sedation/hypnosis using propofol. Frequency dependent changes occurred in EEG amplitude at all levels of sedation, while measures of autonomic circulatory control were relatively preserved until deeper levels of sedation/hypnosis were achieved. This supports a preservation of these neurovegetative control mechanisms during the early stages of CNS depression.

Acknowledgments

The authors acknowledge the assistance of Dr. James Owen, Departments of Pharmacology and Psychiatry, for assistance in the development of the propofol infusion scheme, and Dr. France Varin, Faculté de Pharmacie, Université de Montréal, for propofol blood assays. Baroreflex and spectral analysis software courtesy of Dr. Richard Hughson, University of Waterloo, and Dr. Andrew Blaber.

\section{References}

1 Franks NP, Lieb WR Molecular and cellular mechanisms of general anaesthesia. Nature 1994; 367 : 607-14

2 Kearse LA Jr, Rosow C, Zaslavsky A, Connors $P$, Dershwitz $M$, Denman W. Bispectral analysis of the electroencephalogram predicts conscious processing of information during propofol sedation and hypnosis. Anesthesiology 1998; 88: 25-34.

3 Sneyd JR, Samra SK, Davidson B, Kishimoto T, Kadoya $C$, Domino EF. Electrophysiologic effects of propofol sedation. Anesth Analg 1994; 79: 1151-8.

4 Rocchiccioli C, Saad MAA, Elghozi J-L. Attenuation of the baroreceptor reflex by propofol anesthesia in the rat. J Cardiovasc Pharmacol 1989; 14: 631-5.

5 Cullen PM, Turtle M, Prys-Roberts C, Way WL, Dye J. Effect of propofol anesthesia on baroreflex activity in humans. Anesth Analg 1987; 66: 1115-20.

6 Kamijo $\Upsilon$, Goto H, Nakazawa K, Benson KT, Arakawa $K$. Arterial baroreflex attenuation during and after con- tinuous propofol infusion. Can J Anaesth 1992; 39: 987-91.

7 Sellgren J, Ejnell H, Elam M, Pontén J, Wallin BG Sympathetic muscle nerve activity, peripheral blood flows, and baroreceptor reflexes in humans during propofol anesthesia and surgery. Anesthesiology 1994; 80: 534-44.

8 Robinson BJ, Ebert TJ, O'Brien TJ, Colinco MD, Muzi $M$. Mechanisms whereby propofol mediates peripheral vasodilation in humans. Sympathoinhibition or direct vascular relaxation? Anesthesiology 1997; 86: 64-72.

9 Krassionkov AV, Gelb AW, Weaver LC Action of propofol on central sympathetic mechanisms controlling blood pressure. Can J Anaesth 1993; 40: 761-9.

10 Imbolz BPM, Settels JJ, van der Meiracker AH, Wesseling $K H$, Wieling $W$. Non-invasive continuous finger blood pressure measurement during orthostatic stress compared to intra-arterial pressure. Cardiovasc Res 1990; 24: 214-21.

11 Parati G, Casadei R, Groppelli A, Di Rienzo M, Mancia $G$ Comparison of finger and intra-arterial blood pressure monitoring at rest and during laboratory testing. Hypertension 1989; 13: 647-55.

12 White M, Kenny GNC Intravenous propofol anaesthesia using a computerised infusion system. Anaesthesia 1990; 45: 204-9.

13 Skipsey IG, Colvin JR, MacKenzie N, Kenny GNC Sedation with propofol during surgery under local blockade. Assessment of a target-controlled infusion system. Anaesthesia 1993; 48: 210-3.

14 White PF. Propofol: pharmacokinetics and pharmacodynamics. Sem Anesth 1988; VII: 4-20.

15 Altmayer P, Büch U, Büch HP, Larsen R Rapid and sensitive pre-column extraction high-performance liquid chromatographic assay for propofol in biological fluids. J Chromatogr 1993; 612: 326-30.

16 Chernik DA, Gillings D, Laine $H$, et al. Validity and reliability of the Observer's Assessment of Alertness/Sedation Scale: study with intravenous midazolam. J Clin Psychopharmacol 1990; 10: 244-51.

17 Bertinieri G, di Rienzo M, Cavallazzi A, Ferrari $A U$, Pedotti A, Mancia G A new approach to analysis of the arterial baroreflex. J Hypertension 1985; 3: S79-S81.

18 Blaber AP, Yamamoto $\Upsilon$, Hughson RL. Methodology of spontaneous baroreflex relationship assessed by surrogate data analysis. Am J Physiol 1995; 268: 1682-7.

19 Parlow JL, Viale J-P, Annat G, Hughson RL, Quintin $L$. Spontaneous cardiac baroreflex activity in humans. Comparison with drug-induced responses. Hypertension 1995 ; 25: 1058-68.

20 Yamamoto $\Upsilon$, Hughson $R L$. Coarse-graining spectral analysis: new method for studying heart rate variability. J Appl Physiol 1991; 71: 1143-50. 
21 Smith I, Monk TG, White PF, Ding Y Propofol infusion during regional anesthesia: sedative, amnestic, and anxiolytic properties. Anesth Analg 1994; 79: 313-9.

22 Smith I, White PF, Nathanson M, Gouldson R Propofol. An update on its clinical use. Anesthesiology 1994; 81: 1005-43.

23 Dagnone AJ, Parlow JL. Effects of inhaled albuterol and ipratropium bromide on autonomic control of the cardiovascular system. Chest 1997; 111: 1514-8.

24 Dimier-David L, Billon N, Costagliola D, Jaillon P, Funck-Brentano $C$ Reproducibility of non-invasive measurement and of short-term variability of blood pressure and heart rate in healthy volunteers. Br J Clin Pharmacol 1994; 38: 109-15.

25 Iellamo F, Legramante JM, Raimondi G, Castrucci F, Massaro M, Peruzzi G Evaluation of reproducibility of spontaneous baroreflex sensitivity at rest and during laboratory tests. J Hypertension 1996; 4: 1099-104.

26 Parlow JL, Bégou G, Sagnard P, et al. Cardiac baroreflex during the postoperative period in patients with hypertensive. Effect of clonidine. Anesthesiology 1999; 90: 681-92.

27 Akselrod S, Gordon D, Ubel FA, Shannon DC, Berger $A C$, Cohen RJ. Power spectrum analysis of heart rate fluctuation: a quantitative probe of beat-to-beat cardiovascular control. Science 1981; 213: 220-3.

28 Latson TW, McCarroll SM, Mirhej MS, Hyndman VA, Whitten CW, Lipton JM. Effects of three anesthetic induction techniques on heart rate variability. J Clin Anesth 1992; 4: 265-76.

29 Pomeranz B, Macauley RJB, Caudill MA, et al. Assessment of autonomic function in humans by heart rate spectral analysis. Am J Physiol 1985; 248: H151-H153.

30 Ebert TJ, Muzi M, Berens R, Goff D, Kampine JP. Sympathetic responses to induction of anesthesia in humans with propofol or etomidate. Anesthesiology 1992; 76: 725-33.

31 Galletly DC, Corfiatis T, Westenberg AM, Robinson BJ. Heart rate periodicities during induction of propofolnitrous oxide-isoflurane anaesthesia. Br J Anaesth 1992; 68: 360-4.

32 Howell SJ, Wanigasekera V, Young JD, Gavaghan D, Sear JW, Garrard CS. Effects of propofol and thiopentone, and benzodiazepine premedication on heart rate variability measured by spectral analysis. $\mathrm{Br} \mathrm{J}$ Anaesth 1995; 74: 168-73.

33 Wang DY, Pomfrett CJD, Healy TEJ. Respiratory sinus arrhythmia: a new, objective sedation score. Br J Anaesth 1993; 71: 354-8.

34 Robinson BJ, Buyck HCE, Galletly DC Effect of propofol on heart rate, arterial pressure and digital plethysmograph variability. Br J Anaesth 1994; 73: 167-73.
35 Novak V, Novak P, De Champlain J, Le Blanc AR, Martin $R$, Nadeau $R$. Influence of respiration on heart rate and blood pressure fluctuations. J Appl Physiol 1993; 74: 617-26.

36 Rampil IJ. A primer for EEG signal processing in anesthesia. Anesthesiology 1998; 89: 980-1002.

37 Kearse LA Jr, Manberg P, DeBros F, Chamoun N, Sinai $V$. Bispectral analysis of the electroencephalogram during induction of anesthesia may predict hemodynamic responses to laryngoscopy and intubation. Electroencephalogr Clin Neurophysiol 1994; 90: 194-200.

38 Veselis RA, Reinsel RA, Wronski M, Marino P, Tong $W P$, Bedford RF. EEG and memory effects of low-dose infusions of propofol. Br J Anaesth 1992; 69: 246-54.

39 Seifert HA, Blouin RT, Conard PF, Gross JB. Sedative doses of propofol increase beta activity of the processed electroencephalogram. Anesth Analg 1993; 76: 976-8.

40 Veselis $R A$. The EEG as a monitor of sedation: encouraging progress. J Clin Anesth 1996; 8: S81-S87. 